\title{
Healthy approaches to rare conditions
}

\author{
What do you do if your patient has a condition you've never come across before? Polly Moyer offers \\ encouragement for doctors feeling overwhelmed
}

\section{Polly Moyer}

About one in 17 people will develop a rare condition at some point in their lives, ${ }^{1}$ so you're going to encounter them in your clinics. Because most rare conditions are currently incurable, some general practitioners may feel defeated by them. There's no need to be. But it is worth being aware of some potential pitfalls and how to avoid them.

\section{Acknowledge, don't dismiss}

In 2006, I was diagnosed with mal de debarquement syndrome (MdDS) after a "classic" disembarkation trigger event. Even though I was lucky, being given the diagnosis by an ENT (ear, nose, and throat) consultant relatively quickly, I soon came across the first pitfall-people doubting me.

MdDS is one of many "invisible disabilities," and this can cause some health professionals to doubt or dismiss the symptoms, even after diagnosis. This is understandable, because we look "normal" (and the ruling-out test results are generally "normal" too), but it can be upsetting for patients. Invisible disabilities can result in stigmatisation, prejudice, and discrimination in our daily lives. For example many people with migraine struggle to get suitable adaptations made in their work places. People with MdDS often lose their jobs because they are deemed to be "uninsurable fall risks," yet it is extremely hard for them to claim health benefits. If we find that our doctors also don't acknowledge the symptoms, and the difficulties they cause us, this may feel more shocking than the original diagnosis.

\section{Respect what we know}

I came across the second pitfall when I researched the condition myself. Understandably, some doctors feel frustrated because they simply don't have time to read up on rare diseases themselves. However, with the rise of patient groups, we are likely to be well connected with other people with the same condition and will know what onward referrals, investigations, and treatments have helped them. We will also understand that what helps one person might not help everyone within the same syndrome. We don't want to give up, and we don't want our doctors to give up either.

There has never been a better time to be the doctor of someone with a rare condition. The United Kingdom has an excellent rare diseases strategy that supports a joined-up approach to these conditions and should drive much needed research. ${ }^{2}$ The internet allows patients to connect with relevant clinical researchers, patient groups, and organisations such as Findacure. ${ }^{3}$ Through the patient facing Isabel system many of your patients will be able to self diagnose, which can save a lot of time. ${ }^{4}$

\section{Your role is so important}

For an example of great practice, I wish you could meet my current general practitioner. I am considered "very lucky" to have found her by others with MdDS. Because she knows my sister had similar symptoms for two years (and that migraine runs in the female line in my family) she understands my concerns for my niece. She also commiserates with me that there are no treatment trials in the UK. She accepts the MdDS symptom level calibration sheet, even though it was written by patients, not doctors, and she is happy to hear about the questions posed by the researchers and the progress they're making against the odds. Her approach is to go back through my medical history and try to investigate and then treat the things that rendered me susceptible to MdDS and migraine. She also encourages me to find ways to keep symptom levels as low as possible and celebrates with me when I find something that works consistently. Meanwhile she doesn't need reminding to turn off the fluorescent lights in her surgery, she lets me record our consultations and she never says, "But you look well."

After all this time, I have a doctor I can trust.

Competing interests: I have read and understood BMJ policy on declaration of interests and declare the following interests: I am a cofounder of Action for MdDS UK and have blogged for organisations such as Findacure and Rare Diseases UK.

Rare Disease UK. http://www.raredisease.org.uk/.

2 Department of Health. Rare diseases strategy. 2013. https://www.gov.uk/government/ publications/rare-diseases-strategy.

Findacure. http://www.findacure.org.uk/.

4 Isabel Symptom Checker. http://symptomchecker.isabelhealthcare.com/home/main.

Published by the BMJ Publishing Group Limited. For permission to use (where not already granted under a licence) please go to http://group.bmj.com/group/rights-licensing/ permissions 


\section{What you need to know}

- Patients with "invisible disabilities" can struggle to feel believed, even by family members. We may have experienced this when consulting with doctors and still feel emotionally scarred by the sense of shock this can engender. Showing awareness of these problems will help reassure your patients

- Patients with rare conditions will probably have done lots of research. Please respect what we know and acknowledge our competency. We are trying to help you to help us

- Even if you can't cure us, your role is incredibly important. Rare conditions are generally considered to be "complex," so if you can help us to do the joined-up thinking after referrals to specialists it is a big relief. Your support and encouragement for our hard work in self managing are vital.

\section{Further resources}

- Rare Disease: The GP Role (Health Education England) https://www.youtube.com/watch?feature=youtu.be\&v=1CNGk5lovv4\& app=desktop

- Vestibular Disorders Association http://vestibular.org/

- Action for MdDS UK http://www.actionformdds.org.uk/ 


\section{Figure}

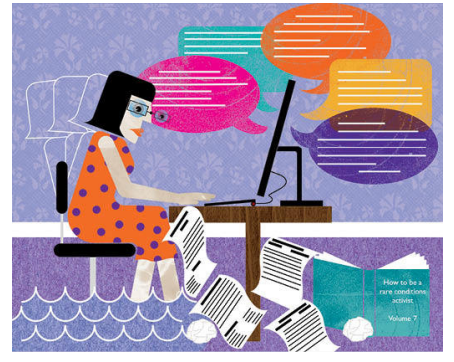

[Image: ROSE LLOYD] 